\title{
PRELIMINARY EXPERIMENTAL WORK ON NANOCOMPOSITE POLYMERS: SMALL PARTIAL DISCHARGES AT INCEPTION VOLTAGE, THE EXISTENCE OF POSSIBLE CHARGING MECHANISMS BELOW INCEPTION VOLTAGE AND THE PROBLEM OF DEFINITIONS
}

\author{
Yuan Zhang - Michael G. Danikas - \\ $\mathrm{Xu}$ Zhao - Yonghong Cheng
}

\begin{abstract}
In this paper, some results are presented from experiments concerning partial discharge (PD) behaviour of epoxy resin samples having $3 w t \%$ nano- and $3 w t \%$ micro-fillers, as well as epoxy samples having $3 w t \% a n d 1 w t \%$ nanoparticles. The nano- and micro-fillers were $\mathrm{TiO}_{2}$ (titania). The main idea is to see whether a sample with PD at its inception voltage, still presents some tendency to charging effects below inception. An effort is being made to relate the present work with previous publications on the same main idea, as well as to previous research performed recently at Xian Jiaotong University, State Key Laboratory of Electrical Insulation and Power Equipment. It is indicated that with the samples investigated, although on some occasions random charging phenomena were observed below the inception voltage, it was not noted the same behaviour as with pure epoxy samples. Finally, a discussion ensues as to the definitions of the phenomena taking place below inception voltage.
\end{abstract}

K e y w ords: small discharges, charging effects, nanocomposites, nanofillers

\section{INTRODUCTION}

Nanodielectrics have been the subject of intensive research in recent years $[1,2]$. Nanofillers can be classified as one-dimensional (thin platelets), two-dimensional (nanowires and nanotubes) and three-dimensional (inorganic oxides) [3]. Their advantages compared to conventional polymers have been pointed out in a number of publications $[4,5]$. Although a great number of people did research on various aspects of nanodielectrics, relatively little has been done wrtthe partial discharge (PD) behaviour of the aforementioned materials. It is well known that partial discharges consist a danger to the insulating materials in general. They degrade their performance and they lead on many occasions to their ultimate failure [68]. Although a great number of people performed research on $\mathrm{PD}$, their mechanisms, the parameters that influence them and their effect on insulting materials, relatively little is known on the possible effects of charging phenomena below the inception voltage. Events which may occur below the so-called inception voltage have been the subject of published work $[9,10]$. In those papers, polyethylene samples were used which had a void. The important aspect of these papers was that pointed electrodes were used touching the opposite void surface in order to simulate local inhomogeneities on the surface of the voids. Such papers indicated that there were some phenomena below the inception voltage which caused similar degra- dation by-products as the inception voltage or even voltages above it $[9,10]$. More specifically, X-ray photoelectron spectroscopy (XPS) spectra of the void surface chemical species indicated that events below inception voltage caused failures similar to PD failures [9].

In the context of the present work, we investigate the possibility of the existence of such charging phenomena with a different electrode arrangement and different insulating materials. The material used was epoxy resin with $3 w t \%$ nanofillers and $3 w t \%$ microfillers, with $3 w t \%$ nanofillers and with $1 w t \%$ nanofillers. The nano- and micro-fillers were of $\mathrm{TiO}_{2}$ (titanium). The electrode arrangement used was a plane/plane arrangement.

\section{EXPERIMENTAL ARRANGEMENT AND RESULTS}

The electrode arrangement consisted of two uniform electrodes. The upper electrode was embedded in pure epoxy resin, with its surface touching the sample, and the bottom electrode was made of brass. The nanomaterial sample had a thickness of $2.5 \mathrm{~mm}$. Partial discharges were recorded with the aid of Tektronix TDS3054B, $500 \mathrm{~Hz}, 5 \mathrm{GS} / \mathrm{s}$. The nanomaterial consisted of samples of epoxy resin with added $3 w t \%$ nanoparticles and 3 $w t \%$ microparticles, of samples of epoxy resin with $3 w t \%$ nanofillers and of samples of epoxy resin with $1 \mathrm{wt} \%$ nanofillers. The nano- and micro-particles were titania

\footnotetext{
* State Key Laboratory of Electrical Insulation and Power Equipment (SKLEIPE), School of Electrical Engineering, Xian Jiaotong Universiy, Xian, Shaanxi 710049, P. R. China
} 


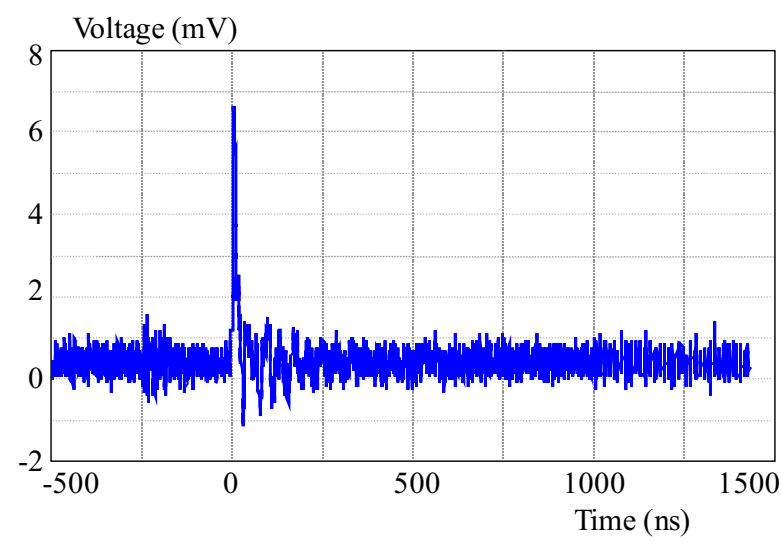

Fig. 1. PD waveform at inception voltage

$\left(\mathrm{TiO}_{2}\right)$. The diameter of the microfillers was $1 \mu \mathrm{m}$ and that of nanofillers was $10 \mathrm{~nm}$. The samples were prepared by using bisphenol A-type epoxy resin (EPON-828), methyl tetrahydropthalic anhydride (MTHPA) as curing agent, silane coupling agent (KH 550), N-N-dimethyl amine as accelerating agent and acetone as solvent.

Our approach was to raise the voltage at inception level, leave it for a while and then decrease it at lower voltages. That was done, for each of the above admixtures, with the sample without a void, with a void and with two voids. In the one-void sample, the void was made at the centre of the sample and was of $1 \mathrm{~mm}$ diameter and $0.5 \mathrm{~mm}$ depth. For the two-void sample, the void sizes were the same as before, with the distance between the voids to be $5 \mathrm{~mm}$. Our approach was not different from what we did in [11], where pure epoxy resin samples were investigated. The aim of this series of experiments was to see whether what was observed with epoxy resin samples and polyethylene samples before that, could also be observed with the samples of epoxy resin mixed with nanofillers (and/or microfillers).

A sample with $3 w t \%$ nano- $+3 w t \%$ micofillers was tested. Its thickness was $2.5 \mathrm{~mm}$. Its inception voltage was $6 \mathrm{kV}$ (Fig. 1), whereas it presented charging phenomena as low as $4 \mathrm{kV}$ (Fig. 2). Lower voltages did not indicate any charging phenomena.

A sample of the same constitution having a cavity of $1 \mathrm{~mm}$ diameter and $0.5 \mathrm{~mm}$ depth, presented an inception voltage at $5.5 \mathrm{kV}$, whereas no charging phenomena were detected at lower voltages.

A sample of the same constitution with two cavities (each of $1, \mathrm{~mm}$ diameter and of $0.5 \mathrm{~mm}$ depth, and a distance of $5 \mathrm{~mm}$ between them), presented an inception voltage at $4.5 \mathrm{kV}$, with no further charging phenomena at lower voltages.

From the above it is noted that on only one occasion charging phenomena were observed at lower voltages.

Furthermore, experiments were performed with a sample having $3 w t \%$ nanofillers. The sample was of $1.8 \mathrm{~mm}$ thickness. It presented an inception voltage at $7.5 \mathrm{kV}$, and further activity at $6 \mathrm{kV}$.
A sample of the same constitution ( $3 w t \%$ nanofillers), having one cavity of $1 \mathrm{~mm}$ diameter and $0.5 \mathrm{~mm}$ depth, presented an inception voltage at $5 \mathrm{kV}$ and further $\mathrm{PD}$ activity at $4 \mathrm{kV}$.

A sample of the same constitution having two cavities (each of $1 \mathrm{~mm}$ diameter, $0.5 \mathrm{~mm}$ depth, and being at a distance of $5 \mathrm{~mm}$ from each other), presented an inception voltage at $4 \mathrm{kV}$, whereas charging phenomena were observed as low as $3 \mathrm{kV}$.

A sample with $1 w t \%$ nanofillers presented an inception voltage at $6 \mathrm{kV}$ with no further activity at lower voltages. The sample had a thickness of $1.6 \mathrm{~mm}$.

A sample with $1 \mathrm{wt} \%$ nanofillers with a cavity of $1 \mathrm{~mm}$ diameter and $0.5 \mathrm{~mm}$ depth, presented an inception voltage of $4.2 \mathrm{kV}$ with no further activity at lower voltages.

A sample with $1 w t \%$ nanofillers having two cavities, with a $1, \mathrm{~mm}$ diameter each, $0.5 \mathrm{~mm}$ depth each and being $5 \mathrm{~mm}$ apart from each other, presented an inception voltage of $4 \mathrm{kV}$, without any further activity at lower voltages.

From the above is fairly obvious that in only very few cases we observed charging phenomena with the above materials under the inception voltage. This may imply that nanomaterials, because of their very structure, produce with more difficulty charging phenomena below the inception level than their counterparts with only base material.

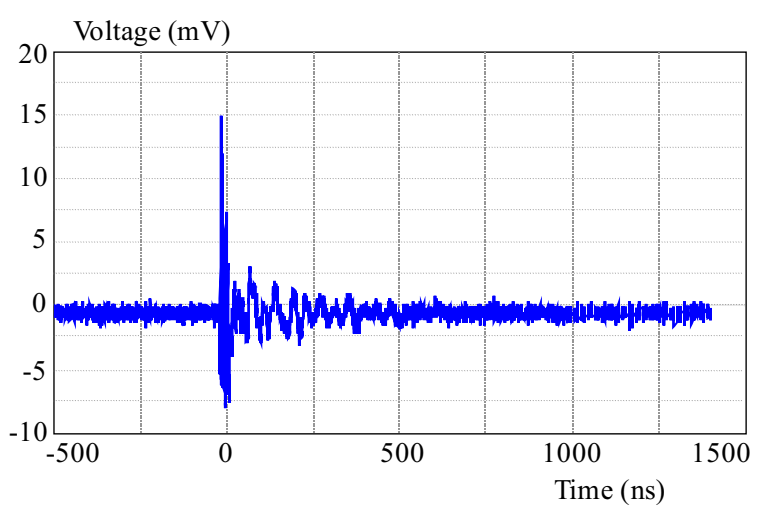

Fig. 2. Discharge (or charging event) waveform below inception voltage

Before the beginning of the experiments, the whole arrangement was calibrated with PDM-II partial discharge calibration pulser. The threshold level of the PD detecting apparatus was $15 \mathrm{pC}$. One may argue that the threshold level is high but one has to consider the noise and possibly carry out the experiments without any external interference. Some people may also argue that, since the sensitivity of the detector is $15 \mathrm{pC}$, what we are actually recording are relatively high magnitude $\mathrm{PD}$ and not very low PD. The gist, however, of our approach is this: no matter what the detecting limit is, we are interested in phenomena which happen sporadically, randomly, below the so-called inception level. On the other hand, the 


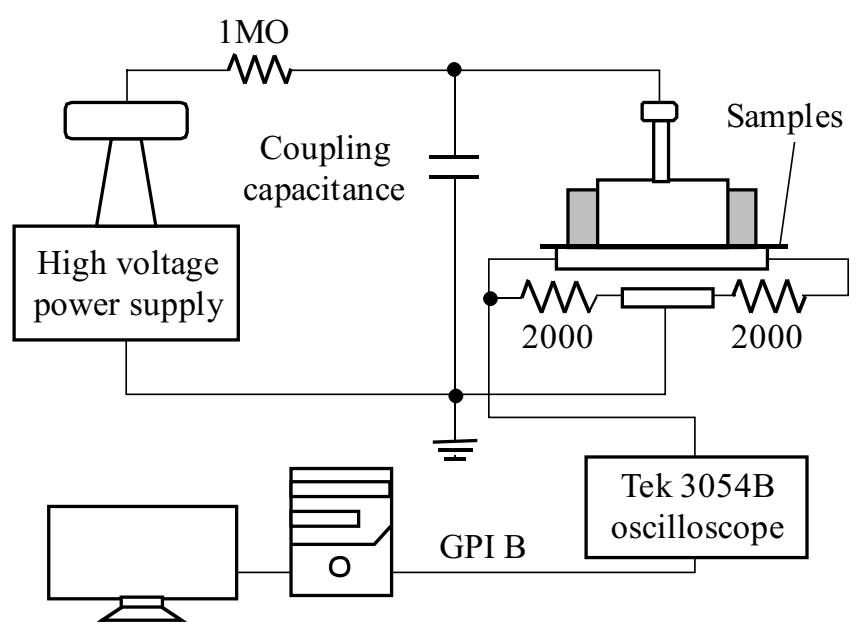

Fig. 3. The detecting circuit for the experiments

detecting circuit we used is very fast, allowing us to detect very fast PD. The detecting circuit can be seen in Fig. 1. For the detection of the PD a TDS 3054B Tektronix $500 \mathrm{MHz}, 5 \mathrm{GS} / \mathrm{s}$ oscilloscope was used. Such a device can register very fast PD (Fig. 3).

The whole approach concentrates as to whether inception voltage with its PD consist a limit below which no long-term danger for the insulation exists. The present work relates to previously published results [11]. One may say that it is a continuation of the previous work, since in [11] pure epoxy resin samples were investigated, whereas in the present paper epoxy resin with nano- and/or microfillers was used.

\section{DISCUSSION}

Nanomaterials are an important area of research nowadays. In the context of this work, a study was undertaken to investigate PD in nanomaterials. Since PD play a definitive role in determining the lifetime of an insulation system and/or insulating material, it was thought appropriate to study PD behaviour in nanomaterials also in conjunction to pure epoxy resin. Direct numerical comparisons of inception voltages between pure epoxy resin and epoxy resin with added nanoparticles and microparticles, cannot be made since the electrode arrangements used on these two occasions were different [11]. Comparisons, however, can be made regarding the behaviour of the two materials at inception and below inception voltage.

The problem of possible charging effects below the inception voltage is a topic discussed in a number of publications $[9,10]$. In conventional polymers, it was indicated that PD occur not only at inception but charging effects take place also below it. Possible reasons for this may be the fact that "something" continues working inside the insulation even if the applied voltage is at relatively low levels, ie ionization may take place even at lower voltages. Such an approach indicates also that an insulation may contain defects that are "energized" even at lower voltages. Does such an approach apply to nanomaterials, such as the one investigated here?

It has been reported, that the nano- and micromixture composites suppress the depths of surface erosion as much as $305 \%$ wrt the base epoxy resin. They present thus a better $\mathrm{PD}$ resistance than that of pure epoxy resin and/or than that of the single nanocomposites or microcomposites [12]. Elsewhere, it was indicated that the introduction of nanofillers reduces polymer space charge and impede the progress of $\mathrm{PD}$ erosion in nanocomposites. Nanofillers segment matrix polymers three-dimensionally and this segmentation gives stronger $\mathrm{PD}$ resistance. The rest of the polymer space is also reduced if interfacial regions increase $[5,13]$. Improvement of the electrical performance of epoxy polymer with nanoand microfillers compared to only microfillers was also reported before [14], but not necessarily of the dielectric strength which showed only marginal improvement [14]. Needless to say that an improvement of the electrical performance of the nanocomposites is dependet on the homogeneous dispersion of the nanofillers in the base material [15].

From the preliminary results, it seems, that with the materials investigated here, no substantial charging effects take place below inception voltage. This is contrary to the previous work done [11] with pure epoxy resin and to the work by others on polyethylene $[9,10]$. There were only on some occasions, when charging phenomena were recorded below inception voltage. The reason may be traced to the different material used this time. Nanofillers have a certain beneficial effect on the electrical performance of the material. This indicates a superior performance from the material with $3 w t \%$ nano- $+3 w t \%$ micro-fillers than the pure epoxy resin, as well of the other nanomaterials tested. It can be due, as was noted in [4], to the bonding strength between fillers and matrices, the inter-filler space or matrix volume surrounded by neighboring fillers, to the morphology in the inter-filler space and to possibility the nanofillers to be closely arranged in the range of nanometers so that they may interact with their surrounding matrices in mesoscopic space. Other 
researchers pointed out, among other aspects, the increment of lifetime of nanofilled epoxies [15], the improvement of PD resistance of nanomaterials [16] and the segmentation of polymer substances into many small areas and/or volumes as an effective means against PD attack [17]. Yet others reported on the large fraction of interface volume and polymer chain entanglement, which hinder the motion of charge carriers [18]. PD resistance of the nanofilled materials may be due to the lower speed of erosion and PD level, which in turn are due to the scattering phenomenon and shielding effect at the surface of the nanocomposite.

All the above tends to explain why the charging phenomena observed with conventional polymers [9-11, 19], were not observed with the material investigated here.

These experiments are by no means conclusive. These experiments are a first approach to see whether with an electrode arrangement developed at SKLEIPE, we are able to see whether pre-discharge phenomena and/or charging events occur below the so-called inception voltage. The experiments until now indicate that the charging phenomena observed before with conventional epoxy resin, were not observed with the epoxy resin in which a mixture of nano- and micro-particles was added. This may be due to the fact that nanomaterials behave in a different way than conventional polymers, ie due to their different structure. The interfacial effect, based on the high fraction of interfacial layers in the nanomaterial, may have played an important role. The small size of the nano-particles may also have played a role since a larger fraction of atoms in the filler particle belongs to the interfacial layer, with the result the fraction of the interfacial layers to increase considerably [20]. It seems that, based on the data available at the moment, some particular effect below the inception voltage was observed on only very few occasions. This may be due to the nature of nanomaterials. The very structure of them, $i e$ the existence of interfacial regions and the close packing between nanoparticles and matrix may not allow phenomena, such as those described in $[8,9,11,19]$ to take place.

One thing that has to be made clear is that, in the context of the present work, is that the phenomena we register below inception seem to have the form of typical PD. A criticism leveled to our approach is that we may register just the extinction voltage, or $\mathrm{PD}$ phenomena in the blurred regime just below inception. However, on the two occasions noted above, the voltage is well below the inception level. To put it in another way, inception and extinction voltages are very close to each other as far as their values are concerned. This is confirmed also in [21], where measured values of PD inception and extinction voltages of samples of polyethylene, leatherite paper and perspex containing various sizes of cavities are mentioned.

The charging phenomenon observed before in $[9-$ $11,19]$ is not observed in the present work with the same frequency and/or intensity. This is not to say that the phenomenon does not exist. It simply says that nanocomposites behave in a somehow different way, ie they do not present as many and intense charging phenomena below the inception voltage as they were observed before with pure epoxy resin or with polyethylene. It may also mean that pure polymers can be more affected by lower voltages and the random charging phenomena than nanocomposites. If this conclusion is reinforced by more research in other nanocomposites, it would be somehow a contribution to our knowledge about pure polymers and nanocomposites. Needless to say, more data is needed in order to reach a definite conclusion on the nanocomposites and their behaviour at lower voltages. As the situation stands right now, no definite conclusions can be drawn since we had in some cases occasional charging phenomena even below the inception voltage.

The experiments performed indicate that below inception voltage occasional PD are possible. They indicate that below inception - on few occasions with nanocomposite polymers - the duration of the applied voltage plays a critical role since occasional PD appear after some time of voltage application. In the experiments described above, random charging activity occurred as the voltage decreased and below the inception level. One may argue that when the voltage goes below inception level, and there are still $\mathrm{PD}$, it is because of the extinction voltage. In other words, one might say that we really witness extinction voltage values and not any charging effects below inception. This, however, contradicts the very definition of PD extinction voltage: namely, that it is the voltage at which repetitive PD cease to occur in the test object, as the applied voltage gradually decreases from a higher value $[22]$.

It must be repeated that these are only preliminary results. Indications of possible charging events exist, although they are fewer than in the case of base polymers. The nanocomposite constitution may have something to do with it. As was pointed out recently, the electrical breakdown path for nanocomposites goes through the resin, at the interface between the resin and the filler [23]. So it may well be that charging events below inception level do not easily develop because of the nanofillers hinder the ionization (or for that matter the weak ionization). Coupling agents, on the other hand, strengthen binding between the polymer matrix and the nanofillers, giving thus a stronger $\mathrm{PD}$ resistance [4].

The role of space charges cannot be underestimated, also in the case of nanocomposites. Space charges may play their role since they are the result of charge transport from the electrode to the defect (or the void). The inception voltage tends to decrease with the increase of the space charge [24]. When PD occur, space charge tends to be transported to PD. However, when PD apparently stop (or are not detected), then there may a space charge accumulation in the sample, and this space charge eventually will be transformed (or developed) into PD [25]. The whole functioning of space charges, however, becomes more difficult in the case of nanocomposites [25]. If we look at the events below inception voltage from this point of view, it becomes apparent that events below inception 
have their own importance simply because when a sample is under an electrical field it never stops accumulating space charge.

A last word on the terminology: it is preferred to use the term "charging event or phenomenon" below the inception voltage instead of "PD below inception voltage". This although, as was pointed out by some researchers, $\mathrm{PD}$ inception voltage is not a constant parameter. PD inception voltage can be altered with time and in fact decreases with ageing [26]. Another proposal for events below inception is to use the term "charge movement" [27]. According to [27], such a term has an analogy to the charge injection and extraction before a tree starts in solid insulation [28]. Yet another proposal for the terminology comes from [29] as "sub-PD". It is our belief that, no matter the terminology used, truth is that "something" occurs even at lower voltages than inception voltage, admittedly with much less frequency in nanocomposite polymers than in base polymers.

\section{PROPOSALS FOR FUTURE WORK}

This work may continue by investigating further the present nanomaterials as well as others. The charging phenomena below inception deserve more attention since, as was indicated before, they can be the cause of insulation deterioration [19]. It would be interesting to see whether the above results may also be obtained without any inclusion of microparticles. Different electrode geometries may be tried out since it is with point-plane electrodes that PD appear in their most aggressive form. A chemical analysis of the byproducts with nanocomposite polymers above and below inception must be tried, especially in view of research published with base polymers $[9,19,30,31]$.

Furthermore, an intensive discussion about the definitions of both discharge phenomena and charging phenomena below inception must be done in order to avoid confusions in terminology. Such an effort has been undertaken long time ago $[32,33]$, but now it should also include phenomena that may appear below inception not only in base polymers but also in nanocomposites.

\section{CONCLUSIONS}

In this paper, some preliminary results with a plane plane electrode arrangement on nanocomposite polymers were reported. Charging phenomena below the inception voltage, although rare, still exist. Nanocomposite polymers present in that a rather different behaviour from conventional polymers. A possible reason for that may be their structure, the close proximity of the nanofillers and the fact that the nanofillers hinder the development of either PD or charging phenomena, ie they hinder ionization. In order to consolidate, however, these conclusions, more work on a variety of nanocomposite polymers has to be done.

\section{REFERENCES}

[1] NELSON, J. K. : Dielectric Polymer Nanocomposites, Springer, Heidelberg, 2010.

[2] DANIKAS, M. G.-TANAKA, T. : Nanocomposites: A Review on Electrical Treeing and Breakdown, IEEE Electr. Insul. Mag. 25 No. 4 (2009), 19-25.

[3] LAU, K. Y.-PIAH, M. A. M.: Polymer Nanocomposites in High Voltage Electrical Insulation Perspective: A Review, Malaysian Polym. J. 6 No. 1 (2011), 58-69.

[4] KOZAKO, M.-KIDO, R.-FUSE, N.-OHKI, Y.-OKAMOTO, T.-TANAKA, T.: Difference in Surface Degradation due to Partial Discharges between Polyamide Nanocomposite and Microcomposite, Ann. Rep. Conf. Electr. Insul. Diel. Phen., 2004, pp. 398-401

[5] TANAKA, T.-IIZUKA, T.: Generic PD Resistance Characteristics of Polymer Nanocomposites, Ann. Rep. Conf. Electr. Insul. Diel. Phen., 2010, pp. 1-4.

[6] TANAKA, T.: Internal Partial Discharge and Material Degradation, IEEE Trans. Electr. Insul. 21 (1986), 899-905.

[7] MASON, J. H. : Enhancing the Significance of PD Measurements, IEEE Trans. Diel. Electr. Insul. 2 (1995), 876-888.

[8] BARTNIKAS, R.: Detection of Partial Discharges (corona) in Electrical Apparatus, IEEE Trans. Electr. Insul. 25 (1990), $111-124$.

[9] BRuning, A. M.-KASTURE, D. G.-CAMPBELL, F. G. C.-TURNER, N. H. : Effect of Cavity Sub-Corona Current on Polymer Insulation Life, IEEE Trans. Electr. Insul. 26 (1991), $826-836$.

10] BRUNING, A. M.-DANIKAS, M. G.: Observations on Discharges above and below CIV in Polymer Insulation, Ann. Rep. CEIDP, Knoxville, Tennessee, USA, October 1991, pp. 638-647.

11] DANIKAS, M. G.-ZHAO, X.-CHENG, Y.: Experimental Work on Epoxy Resin Samples regarding Small Discharges and the Existence of Charging Effects below Inception Voltage, Proc. 2011 Int. Symp. Electr. Insul. Mater. (ISEIM 2011), September 6-10, 2011, Kyoto, Japan, Paper FA6.

[12] LEE, C. H.-PARK, J. J : The Partial Discharge Resistances of Epoxy-nano-and-microcomposites, Trans. Electr. Electron. Mater. 11 No. 2 (2010), 89-91.

[13] TANAKA, T.-KUGE, S. I.-KOZAKO-IMAI, T.-OZAKI, T.-SHIMIZU, T.: Nano Effects on PD Endurance of Epoxy Nanocomposites.

[14] IYER, G.-GORUR, R.-RICHERT, R.-KRIVDA, A.SCHMIDT, L. E. : Dielectric Properties of Epoxy based Nanocomposites for High Voltage Insulation, IEEE Trans. Diel. Electr. Insul. 18 (2011), 659-666.

[15] DI LORENZO, M.-DEL CASALE-SCHIFANI, R.-TESTA, L.-MONTANARI, G. C.-MOTORI, A.-PATUELLI, F.GUASTAVINO, F.-DEORSOLA, F. : Partial Discharge Tests using CIGRE Method II upon Nanocomposite Epoxy Resins, IEEE Int. Conf. Solid Diel., Winchester, 2007, pp. 341-344.

[16] KOZAKO, M.-FUSE, N.-OHKI, Y.-OKAMOTO, T.-TANAKA, T. : Surface Degradation of Polyamide Nanocomposites Caused by Partial Discharges using IEC (b) Electrodes, IEEE Trans. Diel. Electr. Insul. 11 (2004), 833-839.

17] BIN MOHAMAD, M. L.: Partial Discharge Characteristic on Nanocomposite - Natural Rubber Blends as Insulating Material, BSc Thesis, Faculty of Electrical Engineering, Universiti Teknologi Malaysia, May 2011.

18] TAKALA. M. et al : Dielectric Properties and Partial Discharge Endurance of Polypropylene-Silica Nanocomposite, IEEE Trans. Diel. Electr. Insul. 17 (2010), 1259-1267.

[19] TURNER, N. H.-CAMPBELL, F. J.-BRUNinG, A. M.KASTURE, D. G. : Surface Chemical Changes of Polymer Cavities with Currents above and below Corona Inception Voltage, 
Ann. Rep. Conf. Electr. Insul. Diel. Phen. (CEIDP), 18-21 October, 1992, Victoria, B. C., Canada, pp. 687-693.

[20] RAETZKE, S.-KINDERSBERGER, J.: Erosion Behaviour of Nanofilled Silicone Elastomers, Proc. XIVth Int. Symp. High Volt. Eng., Tsinghua University, Beijing, China, August 25-29, 2005, Paper C-09.

[21] GHOSH, S.-KISHORE, N. K. : Modelling of Partial Discharge Inception and Extinction Voltages of Sheet Samples of Solid Insulating Materials using an Artificial Neural Network, IEE Proc. Sci. Meas. Technol. 149 (2002), 73-78.

[22] British Standard BS EN 60270:2001, IEC 60270:2000, High-voltage test techniques - Partial discharge measurements.

[23] ROUX, M. : Reinforced Nanocomposites for Electrical Applications, M. Sc. Thesis, Lulea University of Technology, 2010.

[24] SEGHIER, T.-MAHI, D. MAHI: Investigation into Partial Discharge Dependence in Air Gaps between High Density Polyethylene Tapes, Acta Electrotehnica 49 (2008), 3-13.

[25] DISSADO, L.: Personal Communication, July 2010, and September 2011.

[26] SCHLUPP, P.—BOUCHER, V.-RAIN, P.—PETIT, A. : Partial Discharge Measurements on Glass-Mica-Epoxy Samples for Electrical Insulation During Accelerated Thermo-Oxidative Aging, Int. Electr. Insul. Conf., Birmingham, UK, 2009.

[27] TANAKA, T.: Personal Communication, 13 October 2011.

[28] TANAKA, T.-GREENWOOD, A.: Advanced Power Cable Technology, vol. 1 (Basic Concepts and Testing), CRC Press Inc., Florida, USA, 1983.

[29] SEBO, S. A.: Personal Communication, 10 October 2011.

[30] HARLIN, A.-DANIKAS, M. G.-HYVONEN, P.: Polyolefin Insulation Degradation in Electrical Field below Critical Inception Voltages, J. Electr. Eng. 56 (2005), 135-140.

[31] DANIKAS, M. G.-ZHAO, X.-CHENG, Y.: Experimental Data on Epoxy Resin Samples: Small Partial Discharges at Inception Voltage and Some Thoughts on the Possibility of the Existence of Charging Phenomena below Inception Voltage, J. Electr. Eng. 62 (2011), 292-296.

[32] DANIKAS, M. G.: The Definitions Used for Partial Discharge Phenomena, IEEE Trans. Electr. Insul. 28 (1993), 1075-1081.
[33] DANIKAS, M. G.: Small Partial Discharges and their Role in Insulation Deterioration,, IEEE Trans. Diel. Electr. Insul. 4 (1997), 863-867.

Received 14 September 2011

Yuan Zhang was born in 1987. She received the BS in electrical engineering from Northwestern Polytechnical University, China in 2010. Since 2010, she is a graduate student in Xian Jiaotong University.

Michael G. Danikas received his BSc and MSc degrees from the Dept. of Electrical and Electronic Engineering, University of Newcastle-upon-Tyne, England, in 1980 and 1982, respectively. He received his $\mathrm{PhD}$ from the Dept. of Electrical and Electronic Engineering, Queen Mary College, University of London, England, in 1985. He is currently Professor at Democritus University of Thrace, Dept. of Electrical and Computer Engineering, Xanthi, Greece. During the summer of 2001 he was Visiting Professor in Helsinki University of Technology, High Voltage Laboratory and during the academic year 20082009 he was a Visiting Scholar at Waseda University, Graduate School of Information, Production and Systems. He cooperates with Xi;an Jiaotong University and he spent some time during the summer of 2010 and during the autumn of 2011 working with the State Key Laboratory of Electrical Insulation and Power Equipment (SKLEIPE).

Xu Zhao was born in 1982. He received the BS in electrical engineering from Southeast University, China in 2006. Since 2009, he is a PhD student in Xian Jiaotong University.

Yong-Hong Cheng was born in Anhui, China in 1965. He received the MS and $\mathrm{PhD}$ degrees in electrical engineering from Xi'an Jiaotong University, China in 1991 and 1999, respectively. Since 2001, he is a Professor of Xian Jiaotong University, State Key Laboratory of Electrical Insulation and Power Equipment (SKLEIPE).

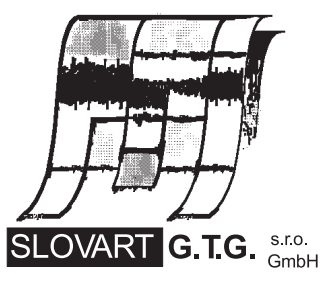

EXPORT - IMPORT
EXPORT - IMPOR T

of periodicals and of non-periodically printed matters, books and CD-ROMs

Krupinská 4 PO BOX 152, 85299 Bratislava 5, Slovakia tel: ++421 263839 472-3, fax: ++421263839485 info@slovart-gtg.sk; http://www.slovart-gtg.sk

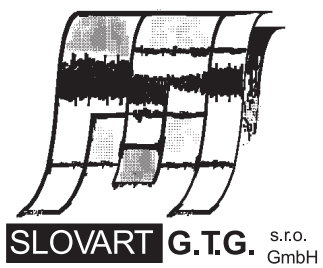

EXPORT - IMPORT 